This is the peer reviewed version of the following article: Enabling and controlling parenthood in publicly provided maternity healthcare: becoming a parent in Finland. Homanen Riikka. Sociology of Health \& Illness, 2017, vol. 39, no. 3, pp. 443-457. It has been published infinal form at http:// dx.doi.org/10.1111/1467-9566.12491. This article may be used for non-commercial purposes in accordance with Wiley Terms and Conditions for Self-Archiving.

The Insitutuonal Repository of University of Tampere

\title{
Enabling and controlling parenthood in publicly provided maternity healthcare: becoming a parent in Finland
}

Riikka Homanen

Gender Studies and Research Centre for Knowledge, Science, Technology and Innovation, School of Social Sciences and Humanities, University of Tampere, Finland

\begin{abstract}
This article discusses practices of parental support in the maternity healthcare provided by the welfare state. Drawing on ethnographic material from clinics in Finland, I discuss maternity healthcare practices and processes as the specific contexts of subjectification to parenthood in the Nordic welfare state. The analysis shows that in both nurses' (work) experience-based knowledge and population statistical knowledge, parental competence is achieved largely through the 'natural' process of experiencing pregnant life. Care practices can be seen as enabling parenthood through respect for this process. Clinics encourage parents-to-be to self-reflect and be self-reliant. Emphasis on self-reflection and self-reliance has previously been interpreted as the state adoption of therapy culture, and as a response to market demands for the welfare state to offer to and require of its citizens more autonomy and choice. I argue, however, that the parental subject emerging from the practices of this welfare service cannot be reduced to a neoliberal reflexive individual for whom parenthood is an individual project and who is to blame for individual shortcomings. Equally, they are no mere disciplined product of governmentality being pushed to conform to an idealised parent figure derived from collective ideas of good parenthood.
\end{abstract}

Keywords: maternity services, parenting/parents, governmentality, care work, empowerment, gender

The healthcare policies of many Western countries increasingly focus on support during the transition to parenthood (Armstrong and Hill 2001, Department of Health 2004, National Research and Development Centre for Welfare and Health 2007, Viitala et al. 2008). The parenthood competences sought in such healthcare policies, however, change according to time and place (Lawler 2000, Vuori 2009). Previous literature on parental support and health care has noted a focus on self-responsibility and autonomy, even in large redistributive welfare states of the Nordic type (Johansson and Hvinden 2007, Lawler 2000, Rose 1990, Sulkunen 2009). This has resulted in the state and public services no longer defining the 'good life' in general, or 'good parenthood' in particular, for their citizens. Instead, they attempt to deliver it indirectly, with responsibility for health and wellbeing shared by peer citizens such as family, friends, communities, the third sector and the private sector (Benhabib 1992, Julkunen 2010, Sulkunen 2009).

However, it would be an exaggeration to state that becoming a citizen and a parent in the Nordic welfare state is nowadays regarded merely as a personal achievement, as might be claimed in some Anglo-American or other European contexts. The welfare service model continues to be both admired as a guarantee of social support and equality and criticised as a mechanism of authoritarian control (Oinas forthcoming, Sulkunen 2009). Parents-to-be are caught between expectations of autonomy and a commitment to collective notions of good parenthood and citizenship (see also Nätkin 2006, Tuori 2007). 
In this article I discuss how everyday practices of parental support in maternity health care straddle the binary of neoliberal individualisation and a collectivist assumption of good (parental) citizenship. By considering the everyday struggle to balance normative pressures towards idealised parental figures with (market) demands for greater choice and autonomy, one can see how this welfare service avoids an either/or response.

The article draws on my research into the institutional constitution of prenatal child-parent relations, based on ethnographic fieldwork at four different maternity healthcare clinics in 2006-2008. It focuses on Finland, where maternity health care provides an excellent opportunity to explore statefunded parental support because it plays a major role in its provision, covering almost $99 \%$ of the population (Viitala et al. 2008).

Up-to-date research on the practices of preventative care to support the transition to parenthood is surprisingly scarce. The extensive literature on parental support in maternity and child health care seems mainly concerned with illnesses or conditions seen as problematic, such as substance abuse, teenage pregnancy and family disadvantage (see Tiitinen et al. 2014). Methods for supporting parenthood in all families through preventative care are, arguably, quite different from specialised care for families already assessed as having problems.

Furthermore, there is surprisingly little research on the particularities of becoming a parent in Nordic countries and the role of welfare services in that process. 'We assume Nordicness, but do not really study it', as Elina Oinas (forthcoming) puts it. She warns that if we do not theorise the contexts of specific subjectification processes, such as becoming a parent, our theoretical tools will often be imported from Anglo-American discussions where the state features little or in a quite different way. I seek to fill both these gaps in sociological knowledge about parental support. I will analyse how healthcare personnel in Finnish maternity healthcare clinics support women and men in practice to become parents. I will then discuss how this statefunded and municipally provided service can be seen as both controlling and enabling parenthood.

\section{Maternity health care in Finland}

In Finland, maternity healthcare services are provided by public health nurses rather than doctors. The service is located in primary health care centred on maternity clinics, rather than in specialised health care provided by hospitals. Pregnant women, and sometimes their partners, meet their appointed nurse approximately 10-13 times. The care is state-funded and provided by municipalities free of charge. It involves the provision of support in the form of advice on matters such as healthy lifestyles and preparing for birth, and the monitoring of somatic changes experienced by the pregnant woman and the baby-to-be. Increasingly attention is also paid to the psychological and home environment by encouraging future parents to consider issues such as parenting choices. Such attention has been termed 'psychosocial' support in policy documents, and is further realised in everyday care in the clinics through nursing interventions (for example, Handbook of Maternity Healthcare 2007, unpublished, National Research and Development Centre for Welfare and Health 2007).

The term 'psychosocial' derives from psychological theory and is now widely used in health care and social work. Psychosocial knowledge reduces parenthood and family life to emotional concerns within immediate social relations and individual behaviour and psychology. This knowledge appeals to the 'social' for support during parenthood from family members, peer groups and 
professionals (Lawler 2000, Nätkin and Vuori 2007). Psychosocial here specifically refers to this restrictive psychological understanding of parenthood and family life.

In addition to meeting pregnant women and their partners individually, the nurses also give counselling classes for groups of parents-to-be, and work in teams with other professionals in the fields of social care and child health care, including social work, family care, child psychology and obstetrics. These teams meet regularly to assess and resolve families' problems.

The care provided in Finland is quite different from that in many other Western countries, which offer more technologically oriented medical care provided by doctors (Benoit et al. 2005: 727-9, Williams 2005). 1 While researchers and activists elsewhere have identified the medicalisation of maternity health care as key to the history of care for pregnant women (Martin 1987, Oakley 1984), this pattern is not fully applicable to Finland (Kuosmanen 2007, Kuronen 1999). 2 Researchers have noted that Finnish maternity health care can best be characterised as a site of activity among women (Kuronen 1999), a site for population politics and policy (Nätkin 2006), or an institution for the management of women as citizens (Wrede 2001).3

Historically, Finnish maternity health care has been one of the key institutions for incorporating women into the nation in order to fulfil their responsibilities as mother-citizens. In the early decades of organised maternity health care, motherhood was protected under a pronatalist policy. The 1970s marked a turning point. Welfare policy shed its pronatalist elements and placed a more genderneutral and individual emphasis on parenthood. In this new model of the family, both parents participate in care (including maternity health care) and they procreate by choice rather than by obligation to the nation (Benoit et al. 2005: 728, Handbook of Maternity Healthcare 2007, unpublished, Nätkin 2006). Despite the emerging emphasis on individual preferences, and even a tone of empowerment, attending maternity health care remains obligatory: women are required to visit a nurse or doctor before the 16th week of pregnancy in order to qualify for maternity benefit.

\section{Ethnography of the (control) practices of the maternity health care institution}

To account for the whole process of care and support, and in order to look directly at the care activities involved, I have used an ethnographic methodology (Harbers et al. 2002). After obtaining formal permission from the Municipal Committee of Research Permissions for the Welfare and Health Institute, and consent from healthcare personnel at the clinics, I conducted 3 months' fieldwork between late 2006 and spring 2008. Consent to participate was sought separately from all the pregnant women and their intimates.

Fieldwork was conducted in short periods of about 5 days. I spent around 1 week per month in each clinic, so that the fieldwork would not exhaust the participants. After approximately 3 months I concluded the fieldwork, as it seemed my observations had covered all the different activities, settings and temporal cycles related to maternity health care (Diamond 2006: 58, Hammersley and Atkinson 1995: 23-54). Furthermore, through video recordings I had collected a large amount of data-intensive material relatively quickly.

This material comprises videotapes and observations from maternity healthcare appointments (69), professional team meetings (11), training sessions for healthcare staff (five) and family counselling classes for parents-to-be (8). Guides and handouts distributed to families, forms kept by the nurses, and local and nationwide guideline materials for care work were also collected. Additional 
documentary material included nursing guides identified by the nurses themselves, and the material they used in their work. Complementary interview data were also collected from public health nurses and pregnant women in order to cover the particular experiences at each field clinic. The pregnant women's interviews are not discussed in this article, as I focus here on the support and control of parenthood practiced by the nurses.

The field clinics are all in one Finnish city with a population of approximately 200,000. The city has more than 20 maternity healthcare clinics in local neighbourhoods, as is common across Finland. The four field clinics operate in separate facilities, which is common in large inner-city clinics. In rural areas with small populations clinics are usually attached to health centres. Clinics are assigned a local client population, with each nurse being responsible for approximately 40 pregnancies and 200 preschool children per year.

In choosing four clinics I aimed to capture the diversity of maternity healthcare practices that could then be explained through their institutional elements. Four field settings provided not just a variety of practices, but also 'ethnographic evidence' (Van Maanen 2006: 16) about the institutional character of those practices that could not be explained away by, say, the nursing style of a particular clinic.

The appointment and team meeting videos were partially transcribed where more detailed documentation was considered relevant. I wrote separate field notes of the video recordings, as full transcriptions would have been unwieldy. The interviews were recorded and fully transcribed.

The analysis was intertwined with the collection of fieldwork material, as is common in (institutional) ethnographic enquiry (Hammersley and Atkinson 1995). Ethnographic research always produces knowledge collaboratively, in that knowledge is generated through the researcher's interaction with the field (Holmes and Marcus 2008). In practice this means repeatedly reframing the ongoing analysis through new knowledge produced in the field. Thus, ethnographic knowledge of how things are actually done is produced without succumbing to the singular voice of social scientific theory, but includes a diversity of voices from the field.

This also enables the researcher to examine how (state or other) power is realised and challenged in specific situational practices. The ethnographic aim is not to make generalising claims about the prevalence of power but to put them to the test. The theoretical framework through which I look at power and control in maternity healthcare considers Foucault's concepts of biopower and biopolitics (Foucault 1990, 2007, 2008)4 as operating 'from practices'. My analysis also owes something to studies of science and technology in (care) practices (for example, Mol 2002, 2008): power relations may have generalising effects on practices, but practices also entail such messiness that no form of power can have a totalising grip on activities and subjectivities. There are multiple, heterogeneous and interconnected orders and out-of-orders at play, and the way they are realised is context-specific. This conceptual apparatus allows one both to document how people are biopolitically governed in (public) institutions and to take seriously the promises of agency made by the institution and its caregivers.

\section{Supporting the process of coming to know parenthood}

In my observation, the transition to parenthood is largely understood at the clinics in terms of the emotional and psychological choices of parents-to-be. The nurses approach parenthood during 
appointment encounters and family counselling classes in terms of psychosocial knowledge. The discussion remains abstract and vague. Nurses talk about 'love', 'attachment' and 'attentiveness', but hesitate to provide specific or concrete content to desirable family life. Even so, there are more and less standardised ways of supporting transitions and screening for problems. Standardised interviews are specifically designed to assess the psychosocial dynamics of families and the support they need. Nurses also have intuitive and practical ways of addressing the transition to life with a baby and parental identity. Some nurses have a structured schedule in which there is a special appointment to discuss all such issues; some trust their instincts and their 'feeling' for families, addressing parenthood issues accordingly. If concerns arise during an appointment, the discussion resembles a therapy session in many respects:

At an appointment a nurse steers a pregnant woman towards reflecting on the whole process of her pregnancy so far by saying: 'It's 30 weeks' gestation now, then. That is quite far along. What do you think about your pregnancy so far? How has it been for you?'

The pregnant woman starts explaining how difficult the beginning of her pregnancy was: she was throwing up all the time, and she remembers that time as 'a black hole'. She states that she does not understand how she got through that phase. The nurse confirms this by commenting that the pregnant woman has certainly been resilient. The woman goes on recalling her troubles in the early stages of her pregnancy. Work was extremely hard. She works at a school, and once she had to leave the classroom because she could no longer fight back the tears. It was because she was so sensitive to the pupils' harsh language. She is now afraid that she failed to be professional. The nurse rushes to ease her mind by telling her that children do not think in terms of being professional or not.

The pregnant woman then states that now there is nothing special going on: 'It's just normal life.' The conversation moves on to feelings and thoughts about the life changes that maternity leave entails. 'How has the change seemed to you?' the nurse asks. The woman replies that so far it feels nice, but it is a bit weird because she has never not been working. The nurse comments that the strange feeling about not working is common to women used to paid work. The woman continues exploring her thoughts: she has been thinking about how to manage mentally when the baby comes. The nurse supports this as something that is good to think about before birth. The pregnant woman responds by saying that she needs to think of 'ways to get out; to be able to breathe'. The nurse stresses the importance of thinking about one's own needs.

The pregnant woman also expresses her worries over the future of her relationship, because she and her partner had been together for only a few months when she got pregnant. The nurse wants to know more, and asks: 'Are you able to talk freely?' The pregnant woman says that they are, which in her opinion is surprising because they have not been together long. At this point the nurse takes up the woman's obvious worry over her 'inappropriately' short relationship with her partner by assuring her that the length of a relationship per se does not denote happiness. (Videotape P36, 30 weeks' gestation, first pregnancy)

The pregnant woman is encouraged to talk about her past and present thoughts, and the experiences and feelings related to them. She is encouraged to reflect on her pregnancy as a mental and 
emotional journey into parenthood. That is also how she orients herself to the actions and questions of the nurse. She has survived the beginning of a pregnancy full of hardship, and is now exploring her inner self to find ways of managing life with a baby ahead with her fairly new partner and outside (paid) work.

The pregnant woman seems to successfully orient herself to the therapy-like conversational support: the conversation flows smoothly and without misunderstandings. The pregnant woman is heard, encouraged and supported emotionally in her struggle to become a mother who is willing and able to fight for a family with two parents, even if she has not had a 'normal pregnancy'. She talks freely with her partner, and thinks about a lot of things with both hindsight and foresight. She seems the ideal client in maternity health care: she is a parent-to-be who can just be supported to help herself, to become self-reliant. The ideal of self-reliance is built into the perception of parenthood as a natural process that is largely expected to unfold by itself. It is characteristic of care work that women's feelings about their changing lifestyle are managed in subtle ways, as in the following description:

It is a parental class at a clinic. The nurse is lecturing about motherhood, with slides. She notes that the father's role is different from the mother's. Women, according to her, have pregnancy-related issues on their minds all the time. She introduces a model according to which there are three phases in pregnancy. In the first phase women withdraw into themselves and need a lot of attention. In the second phase they feel movements, and they should involve men in that. In the third phase it is time to prepare the home for the family.

Next comes a slide entitled 'The birth of motherhood'. Basically, there is motherhood in pregnancy, after delivery and progressively as the child grows. The nurse explains that one's experience of mothering, support from other mothers and the growing of one's own 'maternal instinct' ('special sensitivity and love') are involved in the process of becoming a mother. Before continuing with the slides, she notes that everybody does parenthood in their own way. The same is stressed with the issues of 'a well-functioning family' and 'adequate parenthood', to which are attributed qualities of 'teamwork, communality and individuality, respect, intimacy, attachment, warm atmosphere and trust'. The nurse expresses her preference for an upbringing that relies on 'traditions' and 'communality'. 'Sometimes professional help may be needed, but otherwise parents can trust to their own resources'. (Field notes, 14 May 2007, clinic P)

Implied in this ethnographic snapshot is the expectation that women will acquire a parental identity merely by doing and experiencing pregnancy. Partners (implicitly men), however, appear to need a special invitation to start the process within which paternal selves are conceived. Often this task of inviting men to share parenthood is allocated to pregnant women. They are advised by nurses, for example, to encourage their partners to come to ultrasound screenings to 'see the baby'.

Partners are also enacted as needing to 'get proof' and to make the pregnancy 'real' or 'concrete'. At the same time, however, men are assigned a fairly narrow position in pregnancy, as technologyoriented and knowledge-oriented witnesses who are engaged by appealing to those (stereotypically) masculine traits (Ives 2014, Wall and Arnold 2007). 
Parental counselling, both in classes and at individual appointments, seems to assume that future parents will reflect on their lifestyle 'choices' on the basis of mediated scientific 'facts' about psychosocial concerns and foetal damage, and will then become self-reliant in family life. Parental 'choices' and identities are not treated at the clinics as static, but as achieved through a delicately supported process of coming to know (Kingdon 2007). This may involve reflecting, discussing, inviting partners to participate or just experiencing everyday pregnant life. Parents are often encouraged to do more pregnancy in order to find out their preferences in such matters as lifestyle and parenting.

Support for the process of self-reliance parallels the nurses' experience-based knowledge, gained through working with pregnant women and their partners over a long period of time. This approach dates back to at least the 1930s, when nurses were advised to behave towards pregnant women like friends and share their life burdens (Wrede 2001). Nurses told me that in their experience issues of parenthood become relevant slowly as the pregnancy proceeds and that sometimes people change their minds about things many times before the birth. Encouraging parents-to-be to take time to reflect on their preferences is also in line with parental agency. It supplies parents-to-be with the time and space to creatively build their identity and family life.

\section{'The ethics of not taking a stand'}

Although 'sometimes professional help may be needed,' most of the time 'parents can trust to their own resources' and rely on 'traditions' and 'communality', as the nurse above put it. In my research it became clear that professionals act almost as equal partners with their clients. In contemporary maternity health care, nurses as public servants do not have the authority to act as custodians of the unborn child. Rather, they manage risks and establish security through preventative methods that do not wholly determine wellbeing or 'good' parenthood.

The nurses' delicate approach to supporting the 'natural' process of transition to parenthood can be further characterised by an insistence on shared responsibility. Multiple support groups are necessary, according to the current ideology of parental competence that claims that parents-to-be need to be educated (scientifically) to know their baby(-to-be)'s needs (Hays 1996: 39-43, Vuori 2009). However, it is stressed, professionals should work as equal partners with clients and listen to their experiences. Nurses seem to see themselves as co-participants in pregnancies, facilitators between special services and pregnant people, and mediators of science-based knowledge, rather than as holders of (moral) authority.

Co-participation and encouragement towards autonomy or empowerment are also explicitly emphasised in care guidelines. Below is an extract from the Handbook of Maternity Healthcare, a locally produced and updated intranet guidebook for professionals. The extract advises nurses on how to 'support early interaction'. This passage is titled 'The Expert Role':

Healthcare professionals should think through their conduct and objectives when they are creating a relationship with their client family ... Imaginings, presumptions and attitudes and the expectations of parents affect interactions. Our professional behaviour often implies the role of an expert ...The expert role may lead to professional behaviour that can be harmful to clients and the process of care ...In the expert role, it is easy to take matters into one's own hands, ask questions, make decisions and dictate action. This may lower the clients' self-esteem, make them 
dependent on the professional and increase their passivity, which will further decrease their involvement in the interaction ...A professional needs to be able to create an open and trusting relationship with the client ... The task is to give parents a chance to explore their imaginings in order to anticipate events in their world and to help them form a clear picture of it. This is achieved by changing one's way of doing practical work ...obtaining effective parental guidance skills that will help one to work with parents by supporting them ....and to help parents take care of their own problems more effectively ...taking on the role of helper, and minimising any excessive influence of one's own suggestions and opinions. (Handbook of Maternity Healthcare, printout of municipal intranet document received 8 April 2007)

This passage implies that nurses need to keep some distance if they are to build the autonomy that will enable parents-to-be to become agents of their own (family) life. They are advised not to take a strong stand on issues in order to produce independent parents who reflexively generate their own 'right' ideas of family life and social relations. The appointment videos show that nurses use subtle forms of persuasion; preferences can be articulated without being imposed. Such preferences are often presented in the form of suggestions, backed up by 'scientific knowledge' about psychology or biomedicine. The same issues are approached in a processual way, repeatedly and perhaps from different angles, as in this description:

A pregnant woman, her partner and firstborn have come to an appointment. The nurse wants to know if they have had any help from grandparents. The pregnant woman answers that she is quite bad at accepting help from anybody. The nurse then replies that it's important to remember that this is a phase when one has to think about one's strength. Then she asks the woman if she is one of those people who feel that they have to survive on their own. The woman concurs and the three of them discuss the issue. The nurse repeats her comment that now is a time to 'ponder a little about one's strength', but also reassures the woman about her own competence to evaluate herself: 'Surely you will manage for a while by yourself, but then it's like it does not work any more. I am sure you yourself know best, but there are these family care workers that you might want to keep in mind.... So this is an option as well, especially when the baby is born.'

The woman nods, and then suddenly says that 3 weeks before she had 'a sort of burnout'. She describes her feeling as 'fury' that came after a feeling of tiredness had passed. 'I had an urge to attack ...It woke me up,' she says. The nurse tells the woman that it is a good thing that she recognises these warning signs herself. They return to the issue of the pregnant woman's strength several times during the rest of the appointment.

Finally, the issue is returned to when the nurse asks about the partner's opportunity to take parental leave. It turns out that he is a 'super-entrepreneur' who finds this impossible. The pregnant woman expresses her anxiety about the state of affairs by saying that she is nervous about how they will cope. The nurse empathically turns to the man, saying, 'You must have big pressures about this when you have to be at work and at home,' and advises that talking about these things helps in a partnership.

It turns out that the woman is quite strict about housework. What makes it hard is that their firstborn is constantly hanging on her legs. The nurse gives an explanation from 
developmental psychology about children's phases of interdependence and the feelings of exhaustion often experienced by parents. The nurse then says that this interdependence surely just increases the drain on mental strength, and brings up the family care work service again. She says she wants to give them the contact information anyway, and makes a point about the workers' role as domestic help and not as guests one has to look after. She further emphasises that this sort of assistance is part of preventative care. The pregnant woman finally agrees to accept help by saying that she would be delighted to have the workers over. (Videotape TP24N\&M, 22 weeks' gestation, second child)

This nurse skilfully convinces the pregnant woman to accept domestic help. However, she does not do so by establishing herself as an expert, which would imply authority. Rather, by giving authority to the pregnant woman's own sense of self and reflections, and by empathising with her particular situation, she positions herself as a facilitator who guides from a distance and does not take a strong stand on what should be done. This is further reinforced by her promotion of the pregnant woman's ability to make the 'right choice' in the name of the apparently morally neutral goal of mental health. Ultimately the responsibility for following the advice is left to the pregnant woman, even if the nurse's role in the making the decision is crucial.

What we are witnessing is the emergence of a rationale in welfare services and prevention techniques that insists on persuasion rather than regulations and patronising sermons. This persuasion relies on people's rationality and capacity to come to know their own (family) life.

Pekka Sulkunen (2009) has termed such an approach in preventative social and health policy 'epistolary power'. According to him and to other authors (Julkunen 2010, O'Connor et al. 1999), during the last three decades of the 20th century the Nordic welfare state had to meet a growing demand for risk management, but without determining the 'good life' for its citizens. Citizens' autonomy and privacy must be guaranteed and responsibility decentralised under the welfare state. The response, according to Sulkunen, was 'the ethics of not taking a stand'. This differs from the 'pastoral power' techniques of the nanny welfare state, which infantilises citizens in the name of progress, universal individualism and knowing the 'good life' (Sulkunen 2009: 141-57, Foucault 2007).

\section{Decentralised care}

In the epistolary model of welfare, the rules of conduct are not clearly stated or imposed, and practices of care are constituted within a discourse of empowerment. This does not mean that control is not exercised over the lifestyles of parents-to-be (Sulkunen 2009). However, the control is indirect and does not rely on disciplinary techniques. The principles of agency, autonomy and privacy of the individual (family) require that cooperation at least seems voluntary. Individuals are not directed by others, but direct themselves towards others. Committing oneself voluntarily to accept care and advice, however, simultaneously means attaching oneself to a cluster of common values of health, wellbeing and security in family life. These values have become so broad and vague that they constitute a 'degree of normality: the maximum quality of life that care can offer in each condition' (Sulkunen 2009: 154). This is embodied in buzzwords such as 'adequate parenthood' and 'responsible parenthood'. Responsibility for determining the specific contents of, 
and means of achieving, health, wellbeing and security is shifted onto a number of actors (Julkunen 2010: 104, 216).

This is realised through advisory practices that direct parents(-to-be) towards working with various professionals and laypeople in a community-like formation. Expressions used by nurses, such as 'the whole village' and 'tradition', and their constant concern with getting help from others, illustrate this tendency. Another example is the group work activity common at counselling classes, when parents discuss parenting and the issues raised are then discussed with the nurse. To use Sulkunen's (2009) Foucauldian concepts (Foucault 2007), the nurses guide the discussion not like shepherds, but like apostles: they claim no authority over knowledge in pregnancy, but their different role and knowledge are recognised. The romantic nostalgia of community-like care in relation to abstract issues of parenting is complemented by a trust in the individual common sense of parents(-to-be). They are expected to come to know themselves as parents through 'natural' becoming.

\section{Managing the 'average family'}

When parents-to-be neglect their parental responsibilities, no matter how vaguely those responsibilities have been presented to them, they are given (at the least) a moral lesson. Privacy and autonomy are valued as rights of the individual family, so long as they remain within a 'scale of normality'.

Under the guidelines, nurses are supposed to make numerical assessments based on multiple-choice interviews designed to report on 'mental wellbeing' and 'early interactions' in the family (Instructions for the Numerical Assessments, unpublished, printout received 2007). There is also a more 'traditional' appointment practice of long-term intuitive and affective assessment that achieves the same goals but in a less standardised, visible and measurable way. Those who gain poor scores on the assessment are to be referred for further care, as specified in the manual. Unlike long-term assessment, the form draws on statistical knowledge of the probabilities of multiple risk factors at a given moment in time, and consequently produces 'problem families' or 'families at risk' in need of intervention.

The form thus has the potential to reinforce the power of risk variables and averages produced at the level of population statistics, and to override the local nursing practice's intuitive and situational recognition of problems not included in an assessment form designed around this 'average family' (Bowker and Star 1999, Gubrium and Holstein 1990).

Critical risk scores are often triggered by discussions of single motherhood, mental problems, substance abuse, family violence or other problems predictable at population level. Nowadays, single motherhood alone rarely raises major concerns during appointments. However, if coupled with, say, refusal to accept advice, it may trigger alarm bells. Critical risk scores arise when problematic life conditions have accumulated to the point that the risk of the parents-to-be not coping on their own within the average range of wellbeing seems too high.

Nurses insisted in interviews and discussions that, for example, education and wealth do not determine problems in families. Rather, they claimed that in maternity healthcare practices today, the label 'problem family' could be attached to anybody - outside the scale of 'normality' and in the high-risk zone (Yesilova 2009). What constitutes 'normality' is determined by average 
standards, while an average family is one within a normal distribution on risk scales. This requires breaking down the characteristics of family life and individuals into measurable units and fitting them into a framework of multiple social and health risks in order to generate population-based statistical knowledge for health and social work (Helén and Jauho 2003).

People today, then, are seemingly not categorised a priori as being unable to sustain 'normal' family life. However, some people are constituted 'scientifically' as such through the numerical assessment practice, and are simultaneously enacted as unable to 'naturally' become 'adequate' parents. If one looks at the numerical assessment guidelines it quickly becomes clear that the people most 'at risk' of inadequate family life are likely to be those who (seemingly) lack the ability to self-reflect and converse about problems in intimate family relationships, such as parents-to-be who solve disputes with 'violence' instead of 'constructive and conciliatory methods'. Also, for items on 'early interaction' in the assessment form, the lowest score is given not for having negative mental images of life with a newborn, but for having no images at all. Another clear at-risk group is those who are 'too' dependent on institutional support, such as people in need of a lot of financial or baby care support or social and mental health services (Instructions for the Numerical Assessments, unpublished, received 2007).

Different circumstances are seen as problematic, primarily because they are read as indicating emotional or family relationship problems. Poor housekeeping or financial problems, for eample, may be interpreted as a lack of commitment to the baby's best interests. In other words, certain behaviour and circumstances are seen as signalling poor management of the emotional aspects of family life. Often the solution to circumstances perceived as poor is to offer emotional support rather than financial help (Furedi 2004: 167-8, Yesilova 2009). My observations suggest that whether parents-to-be are referred for further care is also linked to the pregnant woman's ability to accept the emotional support offered. Refusing, or not knowing how to follow, the therapeutic code through self-reflection may lead to care interventions, and also to a psychopathologisation of the transition to parenthood. It seems that reflecting on one's parental journey is sufficient to provide some parental competence. Its absence is considered a risk factor in itself.

\section{Discussion}

Historically, attending and accepting maternity health care in Finland has been almost a civic responsibility (Kuronen 1999, Nätkin 2006). Until the late 20th century the care provided matched Foucault's concept of pastoral power (2007: 115-34) as a mode of the operation of the welfare state. Around that time, welfare policies started to lose their pronatalist elements and gained a gender-neutral and individual emphasis with regard to parenthood. Disciplinary techniques through which biopower was exercised changed accordingly.

The nursing approach of 'not taking a stand' can be seen as a result of this restructuring of the interface between the welfare state and its (parent) citizens (Benhabib 1992, Nätkin 2006, Sulkunen 2009). By exploring everyday care practices one can see that the policy objective of gender equality has actually resulted in more responsibility for women, reproducing maternity health care as a site of women's greater subjectification to parenthood than men (see also Sevón 2009: 86-7, Vuori 2009). The effect of individualisation, in turn, is that parents-to-be are not strongly disciplined to abide by nurses' advice but are expected to act accordingly in a natural process simply by virtue of being informed of things or through subtle forms of encouragement and persuasion. 
This naturalness refers to (population-based, statistical) state knowledge of the laws and regularities of social life - a 'social naturalness' that is believed to 'happen spontaneously when [people] cohabit, come together, exchange, work and produce', as Foucault (2007: 349) describes it. In this new order, the state should manage only in order to facilitate natural wellbeing or create regulations that enable natural regulations to work. In other words, natural phenomena need to be secured through mechanisms of security - in this case, through advice and assessment practices based on (statistical) psychosocial knowledge (Foucault 2007: 352-3). This, indeed, is what Sulkunen's (2009) epistolary power implies.

Relying on parents' self-reflection, the emphasis on psychological aspects of family life and therapy-like assessment encounters in publicly provided care suggest the state adoption of therapy culture (Furedi 2004). The state has attuned to the cultural preoccupation with self and identity by focusing on the management and affirmation of individual subjectivity through therapeutic methods (Furedi 2004, Illouz 2008). Simultaneously, the welfare state's ability to define collective identity has weakened (Furedi 2004: 171). However, the nurses in my study have not lost all power to confer identity: they guide and govern from a distance, and manage people's anxieties to keep them within a scale of normality ('the average family') that comprises self-reliant and self-reflexive people.

While this method of care - therapeutic guidance from a distance - may be beneficial for some, it may not work for others. First of all, as noted elsewhere (Furedi 2004, Illouz 2008), techniques of personal empowerment tend to treat social problems as subjective and emotional problems.

Secondly, people respond differently to the evocation of self-reflexive changes. Mastering the therapeutic code of the appointment interaction requires emotional competence, a term used by Illouz (2008: 200). People refuse, or do not always know how to engage in self-reflection, and this is dependent on their social positions. Further, the 'obligatory' nature of self-reflection - without any clear end-point - may lead to parents merely 'role-playing' reflection (also Reece 2013). Thirdly, the method of persuasion by inviting people to 'freely choose' may be far more effective in producing constraints on individual choices than more disciplinary techniques (which still exist). Finally, if nurses are unwilling to take a stand on family values, the communities parents live in may not be. The nursing approach of 'not taking a stand' may, then, enable and conceal control of reproductive choices and freedoms, especially women's.

Emphasis on self-reliance and empowerment, the adoption of therapy culture and psychological discourse as the model for individualism in public services has been interpreted as a response to the market demand for the welfare state to offer/demand more autonomy and choice for/of its citizens (Benhabib 1992, Foucault 2008, Johansson and Hvinden 2007, Rose 1990, Sulkunen 2009). The state constructs itself in market terms and develops policies that figure citizens as rational selfreliant (economic) actors in every realm of life (Foucault 2008). Social and parental 'naturalness' are seen as dominated by market rationality.

I have considered this carefully and put the powers and governmentalities of parenthood to the test. There certainly are rational (economic) parents being enacted in care practices. The subject of care in parental support, however, cannot be reduced to a neoliberal individual/consumer-citizen (or failure to be one, the at-risk-parent). Not taking a strong stand on 'good' parenthood does not mean that nurses just leave parents-to-be and their communities to figure parenthood out. The care approach is also, and historically, about listening to parents' experiences; and respecting the transition to parenthood as a process of coming to know one's own parental identity by 
experiencing pregnancy supported by a long-term, trusting client-professional relationship. Nobody is left alone to reflect on the cultural competences of parenthood or feelings of inadequacy.

While appointment encounters may fail in many ways, people are not just farmed out for unwanted interventions. Rather, it seems to be the logic of care to try again, attentively and inventively: intervention and referral to specialised care are not merely acts of controlling parenthood.

In conclusion, care that is attentive but does not take a normative stand on parenthood also enables subjectivities that result from contextualised reflection and the practicalities of everyday life. Maternity healthcare nurses play the role of facilitators and co-participants. What emerges is a parent who is neither just the disciplined product of governmentality nor a neoliberal individual solely responsible for their own parental shortcomings. This parental subject is produced in a moment-to-moment process and is dependent in positive ways. Even when they do not conform to the code of conduct, they are not excluded, nor forced into an idealised parental role drawn from collective ideas of 'good' parenthood.

Address for correspondence: Riikka Homanen, Gender Studies, Kalevantie 5, Linna, FI-33014 University of Tampere, Tampere, Finland. Email: riikka.homanen@uta.fi

\section{Acknowledgements}

This research was funded by Academy of Finland Postdoctoral Researcher's Project (project number 274867). I want to thank seminar and workshop participants in Gender Studies at the University of Tampere and at the Gender Institute at London School of Economics for useful comments on the earlier drafts of this article. A special thank you goes to Imogen Tyler and Vicky Singleton (Lancaster University) and John Law (Open University); Tiina Vaittinen and Marja Vehvilfainen (University of Tampere) and Jacob Breslow (London School of Economics) for their insightful feedback on the earlier versions and educated advice. I am also grateful for the constructive criticism provided by the two anonymous reviewers. Finally, thank you to the public health nurses, and the pregnant women, their partners and other intimates who participated in my study for making this research possible.

\section{Notes}

1 In the Nordic context, Sweden and Denmark have similar systems: in Sweden nurse-midwives provide antenatal care, while in Denmark it is nurses. In Norway general practitioners have responsibility for the care. Nurse-midwifery-centredness is not exclusively a Nordic characteristic of maternity health care. For example, in The Netherlands and the UK care is provided by midwives and involves elements of demedicalisation, such as social support. It is not only in Nordic societies that nurses in maternity care offer a more personalised counterbalance to the medical profession, whether as performers of emotional labour (Hardt 1999), as mediators between discourses of normality and risk (Scamell 2011), or as intuitive and practice-oriented decision-makers (Bowker and Star 1999). Here, however, I am empirically studying parental support in the practical context of its provision, not assuming it. Nordicness is thus understood as produced in moment-to-moment everyday practices. 
2 After legislation in 1944 introduced free maternity health care, physicians lost ground to midwives, who gained a state mandate to provide care for pregnant women. The 1972 Public Health Act excluded midwives from maternity health care before birth. This was because policymakers questioned the need for such a high level of competence in preventative care (Benoit et al. 2005: 727-8).

3 Activity among women refers to the central role of women in maternity health care. Population policy politics refers to the close connection of political discourse about population growth and the nation's future with the history of maternity health care after the Finnish civil war of 1918. The institution of public management refers to the insight that maternity health care is a site for managing women in a specifically social liberal way.

4 I understand the relationship between Foucault's concepts of biopower and biopolitics in line with Michel Senellart's commentary on the educational context of Foucault's lectures: 'The analytical perspective of "governmentality" is not .... break in Foucault's work with regard to his earlier analysis of power, but inserted within a space opened up by the problem of biopower ... The shift from "power" to "government" ...result[s] ...from its extension to a new object, the state, which did not have a place in the analysis of the disciplines' (Foucault 2007: 382). Biopolitics, then, refers to the governmentalisation of the state.

\section{References}

Armstrong, C. and Hill, M. (2001) Support services for vulnerable families with young children, Child \& Family Social Work, 6, 4, 351-8. Benhabib, S. (1992) Situating the Self: Gender, Community and Postmodernism in Contemporary Ethics. New York: Routledge.

Benoit, C., Wrede, S., Bourgeault, I., Sandall, J., et al. (2005) Understanding the social organisation of maternity care systems: midwifery as a touchstone, Sociology of Health \& Illness, 27, 6, 722-37.

Bowker, G.C. and Star, S.L. (1999) Sorting Things Out: Classification and Its Consequences. Cambridge: MIT Press.

Department of Health (2004) National Service Framework for Children, Young People and Maternity Services: The Mental Health and Psychological Well-Being of Children and Young People. London: Department of Health.

Diamond, T. (2006) 'Where did you get the fur coat, Fern?' Participant observation in institutional ethnography. In Smith, D. (ed.) Institutional Ethnography as Practice. Lanham: Rowan \& Littlefield.

Foucault, M. (1990) The History of Sexuality: An Introduction. New York: Vintage Books.

Foucault, M. (2007) Security, Territory, Population: Lectures at the Collége de France 1977-1978. Basingstoke: Palgrave Macmillan.

Foucault, M. (2008) The Birth of Biopolitics. Lectures at the Collége de France 1977-1978. Basingstoke: Palgrave Macmillan.

Furedi, F. (2004) Therapy Culture: Cultivating Vulnerability in an Uncertain Age. London: Routledge. 
Gubrium, J.F. and Holstein, J.A. (1990) What Is Family? Mountain View: Mayfield.

Hammersley, M. and Atkinson, P. (1995) Ethnography: Principles in Practice. London: Routledge.

Harbers, H., Mol, A. and Stollmeyer, A. (2002) Food matters: arguments for an ethnography of daily care, Theory, Culture \& Society, 19, 5-6, 207-26.

Hardt, M. (1999) Affective labor, Boundary, 2, 26, 2, 89-100. Hays, S. (1996) The Cultural Contradictions of Motherhood. New Haven: Yale University Press.

Helén, I. and Jauho, M. (2003) Terveyskansalaisuus ja el€am€an politiikka. In Helén, I. and Jauho, M. (eds) Kansalaisuus ja kansanterveys. Helsinki: Gaudeamus.

Holmes, D.R. and Marcus, G.E. (2008) Collaboration today and the re-imagination of the classic scene of fieldwork encounter, Collaborative Anthropologies, 1, 1, 81-101.

Illouz, E. (2008) Saving the Modern Soul: Therapy, Emotions, and the Culture of Self-Help. Berkeley: University of California Press.

Ives, J. (2014) Men, maternity and moral residue: negotiating the moral demands of the transition to first time fatherhood, Sociology of Health \& Illness, 36, 7, 1003-19.

Johansson, H. and Hvinden, B. (2007) Opening citizenship: why do we need a new understanding of social citizenship? In Hvinden, B. and Johansson, H. (eds) Citizenship in Nordic Welfare States: Dynamics of Choice, Duties and Participation in a Changing Europe. New York: Routledge.

Julkunen, R. (2010) Sukupuolen j€arjestykset ja tasa-arvon paradoksit. Tampere: Vastapaino.

Kingdon, C. (2007) Re-visiting choice through 'situated knowledges': women's preference for vaginal or Caesarean birth. $\mathrm{PhD}$ thesis. Lancaster University.

Kuosmanen, P. (2007) 'Mitä ehkäisyy te käytitte?' Asiakaskäytäntölä ja ensimmäisten lesbojen taktiikoita äitiyshuollon tiloissa. In Vuori, J. and Nätkin, R. (eds) Perhetyön tieto. Tampere: Vastapaino. 168- 204.

Kuronen, M. (1999) The social organisation of motherhood: advice giving in maternity and child healthcare in Scotland and Finland. PhD thesis. University of Stirling.

Lawler, S. (2000) Mothering the Self: Mothers, Daughters, Subjects. London: Routledge.

Martin, E. (1987) The Woman in the Body: A Cultural Analysis of Reproduction. Boston: Beacon Press. Mol, A. (2002) The Body Multiple: Ontology in Medical Practice. Durham: Duke University Press.

Mol, A. (2008) The Logic of Care: Health and the Problem of Patient Choice. London: Routledge.

National Research and Development Centre for Welfare and Health (2007) Lastensuojelu 2006. Helsinki: NRDCWH.

Nätkin, R. (2006) Contradiction between gender equality and protection of motherhood: reproduction policy in Finland. In Messner, M. and Wolfgruber, G. (eds) The Policies of Reproduction at the Turn of the 21st Century. Innsbruck: StudienVerlag.

Nätkin, R. and Vuori, J. (2007) Perhetyön tieto ja kritiikki: johdanto perhetyön muuttuvaan kenttään. In Vuori, J. and Nätkin, R. (eds) Perhetyön tieto. Tampere: Vastapaino. 
Oakley, A. (1984) The Captured Womb: A History of Medical Care of Pregnant Women. Oxford: Blackwell.

O’Connor, J.S., Orloff, A.S. and Shaver, S. (1999) States, Markets, Families. Cambridge: Cambridge University Press.

Oinas, E. (Forthcoming) The girls who won the lottery? Empowerment and subjectification in Nordic welfare state girlhood. In Formark, B., Mulari, H. and Voipio, M. (eds) Nordic Girlhoods. In review process. Reece, H (2013) The pitfalls of positive parenting, Ethics and Education, 8, 1, 42 54.

Rose, N. (1990) Governing the Soul: The Shaping of the Private Self. London: Free Association Books.

Scamell, M. (2011) The swan effect in midwifery talk and practice: a tension between normality and the language of risk, Sociology of Health \& Illness, 33, 7, 987-1001.

Sevón, E. (2009) Maternal Responsibility and Changing Relationality at the Beginning of Motherhood. Jyväskylä: University of Jyväskylä Press.

Sulkunen, P. (2009) The Saturated Society: Governing Risk and Lifestyles in Consumer Culture. Los Angeles: Sage.

Tiitinen, S., Homanen, R., Lindfors, P. and Ruusuvuori, J. (2014) Approaches used in investigating family support in transition to parenthood, Health Promotion International, 29, 3, 518-27.

Tuori, S. (2007) Cooking nation: gender equality and multiculturalism as nation building discourses, European Journal of Women's Studies, 14, 1, 21-35.

Van Maanen, J. (2006) Ethnography then and now, Qualitative Research in Organizations, 1, 1, 13 -21 .

Viitala, R., Kekkonen, M. and Paavola, A. (2008) Development of Family Centre Services: Final Report of the FAMILY Project. Helsinki: Ministry of Social Affairs and Health.

Vuori, J. (2009) Men's choices and masculine duties: fathers in expert discussions, Men \& Masculinities, 12, 1, 45-72.

Wall, G. and Arnold, S. (2007) How involved is involved fathering?, An exploration of the contemporary culture of fatherhood, Gender \& Society, 21, 508-27.

Williams, C. (2005) Framing the fetus in medical work: rituals and practices, Social Science \& Medicine, 60, 9, 2085-95.

Wrede, S. (2001) Decentering Care for Mothers: The Politics of Midwifery and the Design of Finnish Maternity Services. Åbo: Åbo Academi University Press.

Yesilova, K. (2009) Ydinperheen politiikka. Helsinki: Gaudeamus. 